УДК 343.244 .24

ПРИМЕНЕНИЕ НАКАЗАНИЯ В ВИДЕ ПРИНУДИТЕЛЬНЫХ РАБОТ НА СОВРЕМЕННОМ ЭТАПЕ

\begin{abstract}
Абрамова Н.Г., Псковский филиал Академии ФСИН России, г. Псков, Российская Федерация, natalika1108@yandex.ru

Босак Е.Е., Псковский филиал Академии ФСИН России, г. Псков, Российская Федерация, pskovbosak@mail.ru

Осколков А.В., Псковский филиал Академии ФСИН России, г. Псков, Российская Федерация, sashuta.oskolkov.89@mail.ru

В настоящей статье посредством анализа научной литературы за последние три года обращено внимание на наиболее обсуждаемые проблемные аспекты назначения и исполнения наказания в виде принудительных работ на современном этапе, что обусловило актуальность выбранной темы. Обосновано закрепление на законодательном уровне возможности назначения судом принудительных работ как самостоятельного вида наказания. Справедливо замечено, что наделение осужденных к принудительным работам признаками лица, конкурентоспособного на рынке труда, увеличит шансы его положительного трудоустройства. Тем самым эффективное отбывание принудительных работ осужденными обеспечит реализацию права потерпевших на возмещение им причиненного преступлением вреда. В статье четко сформулированы предложения, направленные на совершенствование института принудительных работ как вида уголовного наказания. Обоснованы механизмы, которые могут быть реализованы в рамках исполнения данного вида уголовного наказания. Делается вывод о необходимости проведения уголовной и уголовноисполнительной политики по совершенствованию средств исправления и порядка их практического применения с учетом предыдущего отечественного опыта исполнения других видов наказания.
\end{abstract}

Ключевые слова: исправительный центр, осужденный, принудительные работы, трудоустройство, профессиональное обучение.

DOI: $10.21779 / 2224-0241-2020-35-3-128-132$

UDC 343.244.24

\title{
THE USE OF PUNISHMENT IN THE FORM OF FORCED LABOR AT THE PRESENT STAGE
}

Abramova N.G., Pskov branch of the Academy of the Federal Penitentiary Service of Russia, Pskov, Russian Federation,natalika1108@yandex.ru

Bosak E.E., Pskov branch of the Academy of the Federal Penitentiary Service of Russia, Pskov, Russian Federation, pskovbosak@mail.ru

Oskolkov A.V., Pskov branch of the Academy of the Federal Penitentiary Service of Russia, Pskov, Russian Federation, sashuta.oskolkov.89@mail.ru

In this article, through an analysis of scientific literature over the past three years, attention is drawn to the most discussed problematic aspects of the designation and execution of sentences in the form of forced labor at the present stage, which determined the relevance of the chosen topic. It is substantiated that the possibility of a court appointing forced labor as an independent form of punishment is fixed at the legislative level. It has been rightly noted that endowing persons convicted of forced labor with signs of a person who is competitive in the labor market will increase the chances of his positive employment. Thus, the effective serving of forced labor by convicts will ensure the realization of the right of victims to compensation for harm caused by a crime to them. The article clearly formulated proposals aimed at improving the institution of forced labor as a form of criminal punishment. The mechanisms that can be implemented as part of the execution of this type of criminal punishment are justified. The conclusion is drawn about the need for a criminal and criminal executive policy to improve remedies and the procedure for their practical application, taking into account previous domestic experience in the execution of other types of punishment.

Key words: correctional center, convict, forced labor, employment, vocational training. 
Результаты активного применения наказания в виде лишения свободы в предыдущие годы показали не достаточно высокую его эффективность. Этот факт обусловил последующую правотворческую деятельность законодателя, направленную на поиск новых более эффективных средств исправления лиц, преступивших уголовный закон. Новый вид наказания должен был обеспечить достижение его целей при сохранении социальных связей осужденных посредством исключения абсолютной изоляции их от общества. Таким видом уголовного наказания стали принудительные работы, назначавшиеся судами с 1 января 2017 года, войдя в систему наказаний России еще в 2011 году. Учеными и практиками обсуждается этот вид наказания и в настоящее время, что подтверждает актуальность темы настоящей научной статьи.

В качестве учреждений, исполняющих уголовного наказания в виде принудительных работ, применяются исправительные центры (далее - ИЦ) либо изолированные участки исправительных учреждений, функционирующих как исправительные центры (далее - УФИЦ).

Согласно официальным сведениям ФСИН России в настоящее время на территории нашего государства действуют 15 ИЦ и 67 УФИЦ. За последние три года количество лиц, состоящих на учете в указанных учреждениях, существенно увеличилось. Так, если в 2017 году на учете состояло 587 человек, в 2018 - 2501 осужденных, то по состоянию на 1 января 2020 года на учете состояло 5069 лиц, осужденных к наказанию в виде принудительных работ [1].

Несмотря на активное применение судами наказания в виде принудительных работ, его исполнение по-прежнему связано с рядом трудностей. Поэтому в качестве задачи, решаемой в данной работе, авторы видят изучение научной литературы по исследуемому вопросу с целью выявления наиболее значимых проблемных направлений с точки зрения их практического разрешения.

Эффективное функционирование ИЦ (УФИЦ), с одной стороны, гарантирует защиту общества от уголовных правонарушителей, тем самым снижая уровень проникновения в него криминальных элементов, с другой стороны - исполняет наказание, альтернативное лишению свободы [2, c. 54].

Несмотря на сравнительно невысокое число лиц, отбывавших принудительные работы еще два года назад, перспектива его роста в настоящее время подтвердилась [3, с. 7].

Тем не менее, рассмотрим существующие проблемы реализации наказания в виде принудительных работ в России.

О назначении принудительных работ. Отвечая признаку отсутствия изоляции от общества, наказание в виде принудительных работ представляется более гуманным, чем реальное отбывание наказание в виде лишения свободы. Тем не менее, в научной литературе по-прежнему встречаются вы- сказывания о двойственном характере данного вида наказаний. С одной стороны, полная изоляция от общества отсутствует и основное исправительное воздействие возложено на трудовую деятельность осужденного. С другой стороны, проживание в исправительном центре во многом схоже с проживанием в колонии-поселении, где исполняется наказание в виде лишения свободы.

Однако логичным видится вывод А.Л. Белоусова и 3.3. Мамхягова о том, что проведение обязательных удержаний установленной судом части заработной платы осужденного в доход государства делает принудительные работы более суровым наказанием, нежели условное осуждение, либо лишение свободы с отбыванием наказания в колонии-поселении, либо другие виды работ, правовые ограничения которых более гуманны. По мнению исследователей, необходимо обратить внимание на то, что в УК РФ отсутствует перечень конкретных признаков, при наличии которых суд вправе заменить реальную изоляцию от общества на принудительные работы, а не на другое более мягкое наказание [4, с. 440].

Такое положение предопределяет конкуренцию правовых норм, регулирующих назначение названных видов наказаний, а значит, может служить предпосылкой для возникновения коррупционной обстановки и обесценивания эффективности принудительных работ как наказания [5, с. 88].

Видимо, такой негативной ситуации можно было бы избежать в случае закрепления законодательной возможности назначения судом принудительных работ как самостоятельного вида наказания.

В пользу назначения наказания в виде принудительных работ вместо лишения свободы свидетельствуют нормы уголовного и уголовноисполнительного законодательства. Принудительный труд по шесть дней в неделю с утра до вечера обладает в большей степени карательным, воспитательным и исправительным эффектом, чем лишение свободы без работы. Кроме того, за уклонение осужденного от отбывания принудительных работ законодательно предусмотрена ответственность.

Таким образом, двойственный характер принудительных работ ставит под сомнение целесообразность их существования и применения наряду с другими уголовными наказаниями в том виде, в каком они (принудительные работы) регламентированы законодателем в настоящее время.

О трудоустройстве осужденных к принудительным работам. Толкование названия исследуемого в настоящей статье вида наказания предусматривает в качестве основного средства воздействия на осужденного - труд. Достижение цели принудительных работ предполагает обязательное привлечение осужденного к труду. Этим же критерием обусловлена важная роль в исполнении уголовного наказания в виде принудительных работ, которая отведена работодателю. Тем не менее, по- 
прежнему на практике прослеживается явная незаинтересованность организации-работодателя в приеме на работу осужденных, которая предопределена, в частности, двумя факторами.

Во-первых, у большинства осужденных отсутствуют требуемые профессиональные навыки и квалификации [6, с. 271]. А в случае наличия вакантных высокооплачиваемых рабочих мест низкоквалифицированный рабочий не может быть туда устроен.

Современное состояние условий для экономических взаимоотношений в России свидетельствует о наличии проблем с трудоустройством [7, с. 29] не только для правопослушных граждан, но и для нарушителей уголовного закона. Наблюдается отсутствие вакансий на объектах трудоустройства, в том числе и для осужденных, имеющих высшее либо среднее профессиональное образование. В лучшем случае такая категория граждан принудительно обеспечивается низкоквалифицированными рабочими местами. Полагаем, что предоставление осужденному возможности самостоятельно выбирать место работы по профилю своего основного вида деятельности и образования, позволило бы устранить часть проблем по трудоустройству обозначенной категории лиц.

Поиск решения обозначенной проблемы в отношении осужденных к принудительным работам усугубляется тем, что лишь немногие работодатели готовы принять на работу таких лиц. Необходимо помнить о том, что в 2017 году в городе Боровичи Новгородской области прямые протесты в ответ на инициативу ФСИН России об открытии исправительного центра в данном регионе выражали не только потенциальные организацииработодатели, но и органы местного самоуправления, а также местные жители [8, с. 251]. Однако если осужденные к принудительным работам не будут трудоустроены, то утрачивается назначение данного вида наказания [9, с. 101]. Думается, что наделение осужденных к принудительным работам признаками лица, конкурентоспособного на рынке труда, увеличит шансы положительного трудоустройства.

Представляется, что достичь повышения профессионализма принятых на работу осужденных возможно посредством организации администрацией работодателя их обучения для выполнения конкретных видов трудовой деятельности. Для этого необходимо регламентировать процедуру прохождения такого обучения, предусмотреть квотирование рабочих мест для осужденных [10, с. 55].

В 2019 году НИИ ФСИН России провел опрос начальников ИУ (УФИЦ). Результаты анкетирования подтвердили наличие проблем трудоустройства лиц, осужденных к принудительным работам. Респонденты акцентировали внимание на необходимости разработки и принятия нормативного документа, детально регламентирующего порядок привлечения осужденного к труду и осу- ществления удержаний из его заработка, а также компетенцию конкретных должностных лиц, определяющих объекты трудоустройства [11, с. 19].

Кардинальным выходом из ситуации, связанной с проблемами трудоустройства, может быть предложение Ю.А. Кашубы: ученый предлагает все виды уголовных наказаний, связанных с трудом, заменить наказанием в виде принудительных работ. При этом он обосновывает законодательную возможность направления в исправительные центры из мест лишения свободы осужденных к лишению свободы перед условно-досрочным освобождением из колоний. Трудоустройство будет обеспечено для всех осужденных посредством создания передвижных механизированных исправительных центров (далее - ПМИЦ), по техническому функционалу аналогичных передвижным механизированным колоннам (далее - ПМК).

Сегодня ПМК используются для строительства в промышленной заготовке древесины, в строительстве линейных объектов (например, железных дорог, газопроводов, линий электропередач), а также объектов в труднодоступных и малозаселенных районах с суровыми природноклиматическими условиями.

Осужденные, не имеющие профильного образования, могли бы осуществлять свою трудовую деятельность в таких ПМИЦ под руководством высококвалифицированных рабочих [12, с. 15]. Полагаем, что претворение в жизнь этого предложения утвердит позиции исправительных центров в системе учреждений и органов, исполняющих уголовные наказания, а также позволит им осуществлять более эффективную деятельность по исполнению наказания в виде принудительных работ.

Во-вторых, отсутствие инициативы работодателя в приеме на работу осужденных обусловлена тем, что законодателем не предусмотрена возможность увольнения рассматриваемой категории работников. Исключения связаны лишь с нарушением осужденным лицом условий отбывания принудительных работ. Подробно соотношение норм трудового и уголовно-исполнительного законодательства, требующих приведения в соответствие друг с другом, представлено в исследовании Э.В. Лядова [13, с. 173].

О возмещуении материального ущуерба потерпевшему. Перспективное направление назначения наказания в виде принудительных работ - это возможность положительного решения вопроса о возмещении ущерба, причиненного преступлением. Особенно актуален вопрос о возмещении ущерба злостными неплательщиками алиментов, у которых отсутствуют финансовые возможности для этого ввиду своего социального положения. Исполнение принудительных работ осужденными способствовало бы обеспечению прав потерпевших на возмещение им причиненного преступлением вреда не только по указанной категории преступлений, но и по корыстным преступлениям соответствующей 
степени тяжести. Однако уровень заработной платы низкоквалифицированного рабочего не только не позволяет осуществлять возмещение причиненного осужденным ущерба, но и делает невозможным компенсировать расходы по его содержанию. Такое положение вещей еще раз подтверждает необходимость повышения профессиональных навыков осужденных к принудительным работам.

Таким образом, за 2019-2020 годы в качестве особо обсуждаемых проблемных направлений применения принудительных работ ученые и практики выделили вопрос о критериях, определяющих выбор назначения этого наказания, вопросы, связанные с трудоустройством осужденных и с воз- мещением материального ущерба такими лицами. Для фактического достижения цели исправления лиц, осужденных к наказанию в виде принудительных работ, следует проводить уголовную и уголовно-исполнительную политику по совершенствованию средств исправления и порядка их практического применения. При этом необходимо учитывать предыдущий отечественный опыт исполнения других видов наказания, неудачи и успехи зарубежных правоприменителей в обозначенной сфере, а также референции специалистов по психологопедагогическим, социологическим наукам, юриспруденции и др. [14, с. 11].

1. ФСИН: домашний арест основан на добросовестности: интервью. URL: http:/www.fsin.su/ispravitelnye-tsentry URL: https://pravo.ru/news/212775/ (дата обращения: 03.04.2020).

2. Лелик Н.Б. К вопросу об исполнении наказания в виде принудительных работ в исправительных центрах // Уголовно-исполнительная система: педагогика, психология и право: сб. материалов межрегион. науч.практ. конф. (Томск, 20-21 апр. 2017 г.). Томск, 2017. С. 51-54.

3. Абрамова Н.Г. К вопросу о применении уголовного наказания в виде принудительных работ на современном этапе // Функционирование учреждений и органов, исполняющих уголовные наказания, в условиях реформирования уголовно-исполнительной системы: сб. материалов межвуз. науч.-практ. конф. (Псков, 20 окт. 2017 г.). Псков: филиал Академии ФСИН России, 2017. С. 3-7.

4. Белоусов А.Л., Мамхягов 3.3. Проблемы и перспективы применения принудительных работ в российском уголовном праве // Аллея науки. 2019. Т. 3. № 6 (33). С. 437-441.

5. Пимакова О.Г. Актуальные проблемы реализации принудительных работ // Научный вестник Орловского юридического института МВД России им. В.В. Лукьянова. 2019. № 3 (80). С. 87-89.

6. Слабкая Д.Н., Новиков А.В. Принудительные работы. Особенности исполнения данного вида наказания. Экспертное мнение // Вопросы российского и международного права. 2019. Т. 9. № 4-1. C. 266-273.

7. Попова Т.В., Зарипов Р.Р. Проблема трудоустройства осужденных к принудительным работам // Вестник Владимир. юрид. ин-та. 2018. № 3 (48). С. 28-31.

8. Сафаров В. Р., Максютова А. Р., Муртазина Р. Р. Принудительные работы в системе уголовных наказаний: в свете последних изменений // Форум молодых ученых. 2019. № 1-3 (29). С. 249-252.

9. Зубова А.О., Симагин А.О. Исправительные центры как элемент уголовно-исполнительной системы // Юридическая наука и практика: альманах науч. тр. Самар. юрид. ин-а ФСИН России. Самара, 2019. C. 100-102.

10.Спицнадель В.Б. Генезис института уголовного наказания в виде принудительных работ: сб. науч. тр. Северо-Западного ин-та управления РАНХиГС. 2019. Т. 10. № 1-1 (38). С. 44-57.

11.Габараев А.Ш., Питкевич Л.П. Вопросы правового и организационного совершенствования порядка исполнения наказания в виде принудительных работ // Вестник Пермского института ФСИН России. 2020. № 1(36). С. 17-22.

12.Кашуба Ю.А. Возможности создания системы исправительных центров // Человек: преступление и наказание. 2018. Т. 26 (1-4). № 1. С. 11-15.

13.Лядов Э.В. Проблемы практики исполнения уголовного наказания в виде принудительных работ // Юридический вестник ДГУ. Т. 28. 2018. № 4. С. 167 - 175.

Абрамова Н.Г., Босак Е.Е. К вопросу о применении принудительных работ // Преступление, наказание, исправление: IV междунар. пенитенциарный форум (к 140-летию уголовно-исполнительной системы России и 85-летию Академии ФСИН России): сб. тез., выступлений и докл. участников. (Рязань, 20-22 нояб. 2019 г.). Рязань: Академия ФСИН России, 2019. Т. 3. С. 9-12.

1. FSIN: domashnii arest osnovan na dobrosovestnosti: interv'yu. URL: http://www.fsin.su/ispravitelnye-tsentry; URL: https://pravo.ru/news/212775/ (data obrashcheniya: 03.04.2020).

2. Lelik N.B. K voprosu ob ispolnenii nakazaniya v vide prinuditel'nykh rabot $\mathrm{v}$ ispravitel'nykh tsentrakh // Ugolovno-ispolnitel'naya sistema: pedagogika, psikhologiya i pravo: sb. materialov mezhregion. nauch.prakt. konf. (Tomsk, 20-21 apr. 2017 g.). Tomsk, 2017. S. 51-54. 
3. Abramova N. G. K voprosu o primenenii ugolovnogo nakazaniya v vide prinuditel'nykh rabot na sovremennom etape // Funktsionirovanie uchrezhdenii i organov, ispolnyayushchikh ugolovnye nakazaniya, v usloviyakh reformirovaniya ugolovno-ispolnitel'noi sistemy: sb. materialov mezhvuz. nauch.-prakt. konf. (Pskov, 20 okt. 2017 g.). Pskov: filial Akademii FSIN Rossii, 2017. S. 3-7.

4. Belousov A. L., Mamkhyagov Z.Z. Problemy i perspektivy primeneniya prinuditel'nykh rabot v rossiiskom ugolovnom prave // Alleya nauki. 2019. T. 3. № 6 (33). S. 437-441.

5. Pimakova $O$. G. Aktual'nye problemy realizatsii prinuditel'nykh rabot // Nauchnyi vestnik Orlovskogo yuridicheskogo instituta MVD Rossii im. V.V. Luk'yanova. 2019. № 3 (80). S. 87-89.

6. Slabkaya D.N., Novikov A.V. Prinuditel'nye raboty. Osobennosti ispolneniya dannogo vida nakazaniya. Ekspertnoe mnenie // Voprosy rossiiskogo i mezhdunarodnogo prava. 2019. T. 9. № 4-1. S. 266-273.

7. Popova T.V., Zaripov R.R. Problema trudoustroistva osuzhdennykh k prinuditel'nym rabotam // Vestnik Vladimir. yurid. in-ta. 2018. № 3 (48). S. 28-31.

8. Safarov V.R., Maksyutova A. R., Murtazina R.R. Prinuditel'nye raboty v sisteme ugolovnykh nakazanii: v svete poslednikh izmenenii // Forum molodykh uchenykh. 2019. № 1-3 (29). S. 249-252.

9. Zubova A. O., Simagin A. O. Ispravitel'nye tsentry kak element ugolovno-ispolnitel'noi sistemy // Yuridicheskaya nauka i praktika: al'manakh nauch. tr. Samar. yurid. in-a FSIN Rossii. Samara, 2019. S. 100-102.

10. Spitsnadel' V.B. Genezis instituta ugolovnogo nakazaniya v vide prinuditel'nykh rabot: sb. nauch. tr. Severo-Zapadnogo in-ta upravleniya RANKhiGS. 2019. T. 10. № 1-1 (38). S. $44-57$.

11. Gabaraev A. Sh., Pitkevich L. P. Voprosy pravovogo i organizatsionnogo sovershenstvovaniya poryadka ispolneniya nakazaniya v vide prinuditel'nykh rabot // Vestnik Permskogo instituta FSIN Rossii. 2020. № 1(36). S. 17-22.

12. Kashuba Yu. A. Vozmozhnosti sozdaniya sistemy ispravitel'nykh tsentrov // Chelovek: prestuplenie i nakazanie. 2018. T. 26 (1-4). № 1. S. 11-15.

13. Lyadov E.V. Problemy praktiki ispolneniya ugolovnogo nakazaniya $\mathrm{v}$ vide prinuditel'nykh rabot // Yuridicheskii vestnik DGU. T. 28. 2018. № 4. S. $167-175$.

14. Abramova N.G., Bosak E.E. K voprosu o primenenii prinuditel'nykh rabot// Prestuplenie, nakazanie, ispravlenie: IV mezhdunar. penitentsiarnyi forum (k 140-letiyu ugolovno-ispolnitel'noi sistemy Rossii i 85-letiyu Akademii FSIN Rossii): sb. tez., vystuplenii i dokl. uchastnikov. (Ryazan', 20-22 noyab. 2019 g.). Ryazan': Akademiya FSIN Rossii, 2019. T. 3. S. 9-12. 